\title{
UM ESTUDO SOBRE PROJETOS DE ROBÓTICA NOS ANOS FINAIS DO ENSINO FUNDAMENTAL
}

\author{
Vinícius Silveira Magnus - PPGECIM -ULBRA - vinimagnus@ gmail.com \\ Marlise Geller - PPGECIM - ULBRA - marlise.geller@gmail.com
}

Resumo: Este artigo é um recorte da pesquisa de Mestrado que objetivou implementar projetos de robótica com alunos dos Anos Finais do Ensino Fundamental com a aplicação de atividades que abrangem a lógica de programação e a robótica envolvendo conceitos das áreas de Física e Matemática. Os conceitos trabalhados abordaram, por meio da resolução de problemas, a construção de protótipos escolhidos pelos alunos com a plataforma de prototipagem eletrônica Arduino. Os resultados obtidos apontam indicativos de que conceitos científicos emergem no trabalho com a robótica e que muitas são as possibilidades de ações com a abordagem proposta, como o desenvolvimento do trabalho em grupo, o estímulo do raciocínio lógico.

Palavras-chave: Robótica. Lógica de Programação. Projeto de Trabalho.

\section{IMPLEMENTATION OF A ROBOTIC PROJECT IN LAST YEARS OF ELEMENTARY SCHOOL}

\begin{abstract}
This article is part of a MSc dissertation that developed robotics projects with students in the final years of elementary school with the purpose of applying activities that include programming logic and robotics with the support of knowledge in the fields of Science and Mathematics. This project was focused on development and problem solving using Arduino, an electronic prototyping platform. During the analysis, it was possible to identify the actions that made it possible to develop, apply, and evaluate the project, mainly focusing on the strengths and/or weaknesses of the use of robotics. Our results suggest that scientific concepts appear while developing robotics projects and there are many possibilities related to this approach.
\end{abstract}

Keywords: Robotics. Logic Programming. Work Project.

\section{INTRODUÇÃO}

A partir de um recorte da pesquisa de Mestrado, do Programa de Pós-Graduação em Ensino de Ciências e Matemática - PPGECIM-ULBRA, que buscou analisar a implementação de projetos de trabalho nos Anos Finais do Ensino Fundamental e suas potencialidades, entendemos que a tecnologia pode ser um objeto transformador, agregando diferentes possibilidades para o ensino e para a aprendizagem, por meio do desenvolvimento da lógica de programação, instigando a curiosidade científica e o raciocínio lógico (Magnus, 2015).

Nesse cenário, a robótica constitui-se em uma oportunidade de unirmos tecnologia em sala de aula, com algumas premissas teóricas e práticas de ensino, que exijam do aluno o desenvolvimento do raciocínio lógico. Aliado a isso, a resolução de problemas, presente na Matemática, utiliza um modo de pensar, em que o aluno é instigado a resolver determinadas situações com o conteúdo proposto pelo professor (Craig, 2012).

\section{ROBÓTICA E EDUCAÇÃO}

Nunes (2011) defende o ensino de conceitos básicos da computação, no Ensino Fundamental e Médio, destacando a importância do desenvolvimento de uma educação 
com mais qualidade por meio de modelos de computação, algoritmos, complexidade computacional, autômatos, linguagens e arquitetura de computadores, entre outros. Wing (2006) discorre sobre a abrangência do ensino de Computação, levando ao desenvolvimento de um subconjunto de competências e habilidades, denominado de pensamento computacional. Esse pensamento envolve competências relacionadas à abstração e à decomposição de problemas cuja resolução pode ser efetivada por meio de recursos computacionais e estratégia algorítmicas.

Uma forma de desenvolver o pensamento computacional é por meio da realização de atividades baseadas na lógica de programação. Podemos entender a lógica de programação como uma forma de se trabalhar o pensamento computacional de maneira muito abrangente. Ao se trabalhar robótica com os alunos, abordamos o ensino da lógica como premissa para o desenvolvimento de soluções computacionais para o processo. A lógica, nesse caso, é desenvolvida com a proposta de permitir a busca de soluções para determinadas situações que vão surgindo ao longo do processo.

Em um cenário educacional, no qual o aluno é produtor de suas próprias soluções, o que é muito fortemente mostrado na resolução de problemas, a robótica se mostra um recurso com potencial para o processo de ensino e de aprendizagem. A robótica pode incentivar o aluno a buscar soluções uma vez que lhe permite a construção dessas soluções e o instiga a ir em busca de informações necessárias para realizar determinada tarefa (Craig, 2012).

Para um projeto de robótica ser colocado em prática, são necessários componentes físicos chamados de hardware e componentes lógicos que serão definidos com uma linguagem de programação. Há no mercado diversas tecnologias em termos de hardware para o desenvolvimento de projetos com robótica. Uma das mais conhecidas e populares atualmente é o Arduino que, por se tratar de uma plataforma de prototipagem eletrônica de hardware livre, tem conquistado espaço em diversas áreas, incluindo a educação. $\mathrm{O}$ objetivo do projeto Arduino é criar ferramentas acessíveis, com baixo custo, flexíveis e fáceis de serem usadas por profissionais de Informática e usuários com conhecimentos intermediários (ou avançados) de Informática, principalmente por aqueles que não têm acesso a controladores mais sofisticados e a ferramentas mais complexas. Essas características tornam a plataforma viável de ser empregada na educação devido à difusão do software livre e, principalmente, da evolução do hardware livre (Craig, 2012; Fernandes, et al., 2012; César, 2004).

\subsection{Projetos de Trabalho no contexto educacional}

O desenvolvimento de projetos de trabalhos conquistou espaço no cenário educacional devido às diversas possibilidades para sua realização. Destacando-se exemplos como, trabalhar diversos conteúdos relacionados às disciplinas, abordar temas extracurriculares e experimentar tendências de ensino, já que sua construção promove um desenvolvimento mais flexível e aberto dos conteúdos escolares. Segundo Hernández e Ventura (1998), a organização de projetos de trabalho se baseia nas descobertas espontâneas dos alunos e requer, durante as diferentes fases e atividades, uma consciência de seu processo de aprendizagem, exigindo do professor uma resposta aos desafios de estruturação de conteúdos escolares de maneira mais aberta e flexível.

Os projetos de trabalhos também são propostos por Zabala (2008), procurando suprir as necessidades de desenvolver conteúdos escolares organizados na perspectiva da globalização.

Os projetos de trabalhos apresentam alguns pontos relevantes a serem observados. Dentre os que serviram como base para este estudo, destacam-se: a escolha do tema, a 
atividade do docente após a escolha do projeto, a atividade dos alunos após a escolha do projeto e busca das fontes de informações.

Ainda na perspectiva dos projetos de trabalho e de conceitos oriundos das áreas de Física e Matemática que emergiriam nesta investigação, infere-se que "[...], o êxito na re(solução) de problemas matemáticos e outros problemas com a ajuda da matemática, dependerá, em grande medida, do trabalho cooperativo, sobretudo, quando se trata de matemática escolar” (Mora, 2004).

\section{PERCURSO METODOLÓGICO}

O percurso metodológico adotado contemplou, em uma abordagem qualitativa, aspectos mais flexíveis (Bauer; Gaskell, 2010), tanto por parte do pesquisador, quanto dos alunos envolvidos, em relação aos conteúdos que foram emergindo das dúvidas e curiosidades do próprio grupo, pois os alunos decidiram quais problemas desenvolveriam no contexto da robótica. Para tanto, a aplicação foi dividida em duas partes distintas:

- Parte 1 com 4 encontros, totalizando 15 horas, envolvendo a:

- utilização de um ambiente para introduzir conceitos de lógica de programação, sendo trabalhada a lógica com software de construção de algoritmos em blocos e o próprio ambiente de desenvolvimento (IDE) do Arduino ${ }^{1}$;

- ambientação do aluno com a robótica por meio do estudo das estruturas do Arduino;

- realização de atividades básicas da robótica com o uso de sensores de entrada, processamento dessa informação e resultado através de componentes de saída.

- Parte 2 com 8 encontros, totalizando 27 horas, abrangendo:

- utilização do ambiente de desenvolvimento do Arduino (IDE) com a lógica de programação;

- construção de soluções para resolução de problemas que emergiram das propostas de trabalho do grupo;

- uso de diversos dispositivos aliados ao Arduino e seus componentes, como motores e engrenagens;

- utilização do Lego MindStorms para montagens de projetos, nos quais foi empregada a parte de blocos de montagens do Kit. Para a programação, foram utilizadas as placas do Arduino.

O ambiente de aplicação do projeto foi a Escola Municipal de Ensino Fundamental Santa Rita, com, aproximadamente, 250 alunos e cerca de 25 professores da rede pública municipal que está localizada na cidade de Torres-RS, no Bairro Santa Rita.

Participaram da pesquisa, voluntariamente, 14 alunos do $6^{\circ}, 7^{\circ}$ e $8^{\circ}$ anos do Ensino Fundamental, com idades entre 11 e 14 anos, identificados no texto como Aluno A, Aluno B, ..., Aluno N. Todos os encontros foram filmados, com a devida autorização dos responsáveis.

Os recursos utilizados para a realização das atividades com os alunos foram:

- Laboratório de informática com computadores com Linux Educacional com acesso à internet, disponibilizado pela própria escola;

\footnotetext{
${ }^{1}$ Segundo a comunidade Arduino.cc (2015), o Arduino é uma plataforma de prototipagem eletrônica de código aberto, baseada em hardware e software de fácil uso. As placas Arduino são capazes de interagir com sensores de entrada na captura de informações, realizar o processamento e convertê-los em ações de saída.
} 
- Placas Arduino Uno: IDE de desenvolvimento do Arduino, componentes de Arduino, leds, botões, motores, rodas.

- $\quad$ Kits do Lego MindStorms, do acervo do Laboratório de Estudos de Inclusão - LEI do PPGECIM-ULBRA.

A análise dos dados ocorreu a partir de três elementos:

- $\quad$ filmagens, organizadas seguindo a ordem das aulas e, posteriormente, serviram para observar as atividades realizadas e o seu desenvolvimento, analisando falas, gestos e comportamento dos alunos;

- questionários, aplicados ao iniciar o projeto e ao final de cada encontro, objetivando buscar informações sobre os conhecimentos dos alunos a respeito de tecnologia e robótica, além de também verificar a percepção final sobre o projeto;

- diário de bordo, descrição das atividades planejadas para cada aula, contendo, posteriormente, registros das impressões do pesquisador, comentários e/ou dúvidas dos alunos.

\section{IMPLEMENTAÇÃO DO PROJETO}

Para a implementação do projeto, as atividades foram organizadas em duas etapas. $\mathrm{Na}$ primeira, o foco estava na ambientação com os componentes do Arduino, com a programação e a lógica de programação e com a definição de conceitos sobre a robótica, a fim de proporcionar aos alunos uma contextualização do projeto. Na segunda etapa, os alunos constituíram-se em autores com autonomia para o desenvolvimento de projetos que se originassem de suas sugestões e seus desejos, na perspectiva de Papert (1994) por meio do qual o aprendiz tem um papel ativo no processo de construção de conhecimentos.

\subsection{Primeira fase do projeto}

Na primeira aula, foi realizada uma introdução geral sobre o que era o projeto, como ele se desenvolveria e o que se poderia criar em conjunto com os alunos, contemplando conceitos de robótica, apresentação da plataforma Arduino, demonstração dos kits do Lego como parte estrutural. Também foram analisados alguns exemplos para que os alunos tivessem um melhor entendimento sobre a estrutura e montagem do Arduino, uma vez que o grupo de aluno nunca tivera contato com esta tecnologia.

No primeiro experimento, a partir de um exemplo dado, os alunos puderam elaborar seu primeiro código, cujo objetivo era acender e apagar um led no pino $13 \mathrm{em}$ um determinado instante de tempo, como mostra a Figura 1.

Figura 1 - Estrutura e código desenvolvido para acender o pino 13

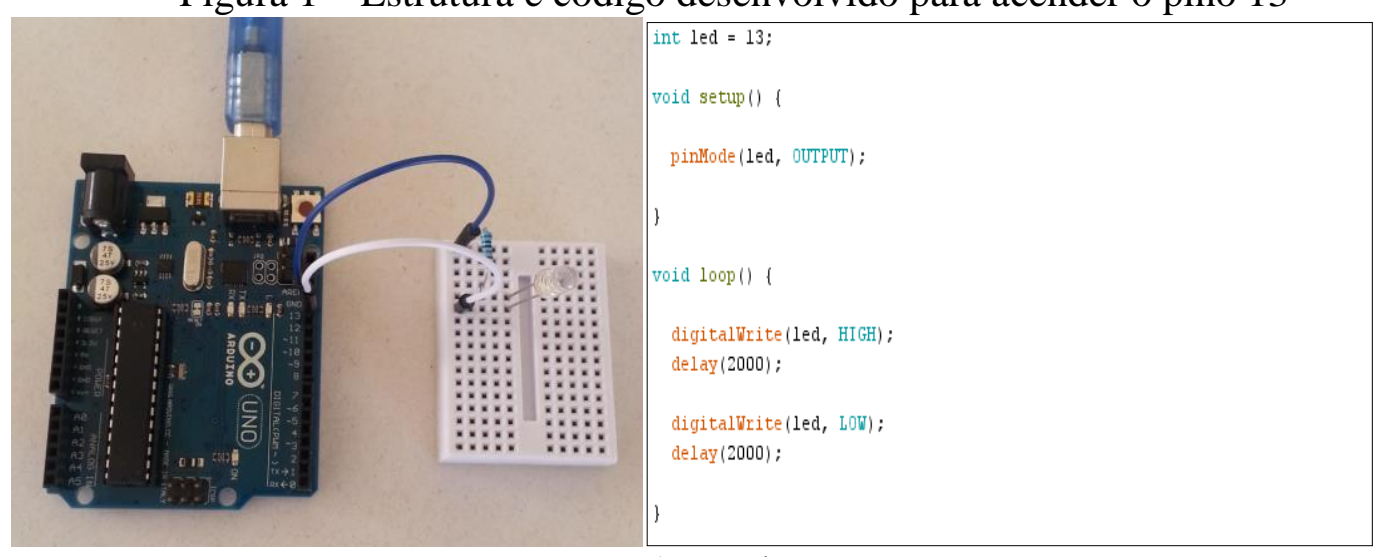

Fonte: A pesquisa 
Nas aulas seguintes, após explicações mais detalhadas sobre os conceitos da placa Arduino e seus elementos, foram realizadas duas práticas. Na primeira, utilizamos a estrutura condicional com os comandos if-else para fazer os leds alternarem de status (ligados ou desligados) após o teste condicional.

$\mathrm{Na}$ segunda prática, empregamos a estrutura de condição dos comandos if-else para fazer um led acender com o clicar de um botão, com o intuito de criar um pequeno projeto com um botão para acender o led, enquanto estivesse pressionado.

Apresentamos os conceitos das estruturas de repetição while-do e for que são as mais conhecidas e utilizadas na programação. Vimos então, a necessidade de demonstrá-las, primeiramente, em algo similar ao português estruturado (técnica de se escrever códigos em português), para o melhor entendimento das estruturas.

Para a elaboração da estrutura do comando for, fez-se necessária a explicação pormenorizada sobre a parte de controle, descrevendo detalhadamente os três itens da estrutura ( $\mathrm{i}=0 ; \mathrm{i}<5$; $\mathrm{i}++)$.

No momento de se trabalhar com o incremento e comparação de variáveis, surgiram questionamentos como o do Aluno B sobre o que era um int e o porquê de usarmos inteiro. Os Alunos D e H relataram algumas questões e dúvidas sobre as variáveis, "se a variável $\boldsymbol{i}$ no Arduino era igual a variável a de uma função do tipo $\boldsymbol{a} \boldsymbol{x}+\boldsymbol{b}$, por exemplo".

Desta forma, houve necessidade de elaborarmos atividades para ensinar funções. $\mathrm{Na}$ programação podemos caracterizá-las como sub-rotinas que executam tarefas em particular, às quais podemos chamar a qualquer momento dentro de um algoritmo. A partir das análises das aulas anteriores, vimos a necessidade de aprofundar também o conceito de variáveis.

A fim de abordar o conceito de função, propusemos uma tarefa em que os leds deveriam ligar e desligar a partir de funções. Nesse momento, os alunos tiveram dificuldade em definir as funções. O entendimento, por parte dos alunos, dos conceitos de função na programação, em que função é uma sub-rotina que pode ser executada ou "chamada" a qualquer momento no algoritmo, trouxe dúvidas. Assim, houve a necessidade de uma articulação com conceitos matemáticos. A partir desta constatação, se criou um algoritmo que, por meio de dois valores realizava as quatro operações básicas, sendo as operações básicas matemáticas, transformadas em quatro funções, como mostra a Figura 2.

Figura 2 - Função de soma no Arduino e estrutura lógica de uma função

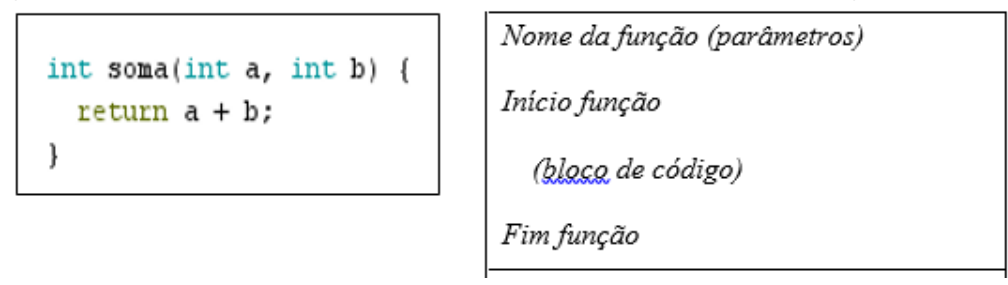

Fonte: A pesquisa

Ao finalizar a atividades com funções, partimos para a criação de algoritmos que trabalhassem com mais variáveis e algumas operações matemáticas, como subtração, multiplicação e divisão. As operações foram feitas com variáveis de valores prédefinidos.

Ao encerrar a primeira fase do projeto, retomamos a perspectiva de Papert (1994), cuja ideia é que a construção do conhecimento aconteça a partir do aluno, que poderá desenvolver algo de seu interesse e que faça sentido para ele. Assim, prepusemos uma discussão mais ampla sobre as atividades que seriam feitas na segunda fase. Para tanto, 
organizamos uma mesa redonda com os alunos questionando quais seriam os projetos que eles gostariam de desenvolver. Ao final, o grupo concordou em desenvolver a construção de uma estrutura que simulasse um carro que se locomovesse para um local desejado pelo condutor.

Essa visão também segue a linha dos projetos de trabalho apresentada por Hernández e Ventura (1998). Optamos por fazer a abertura do tema apenas na segunda fase, por entendermos que a primeira fase é uma composição importante para o levantamento de dados para este trabalho. Também consideramos que as atividades seriam a base para os alunos entenderem os mínimos conceitos sobre robótica, formando uma noção desse ambiente a fim de discutir, com mais clareza, sobre o que gostariam de realizar.

\subsection{Segunda fase do projeto}

Tomando como premissa o tema e a proposta definidos pelos alunos, começamos a pesquisar os materiais necessários para a sua realização, e as sugestões de tarefas que melhor se enquadrariam à escolha dos alunos. Para esta segunda fase, fez-se necessário a aquisição de duas estruturas completas de chassi, cada uma com os seguintes componentes (Figura 3):

Figura 3 - Kits de chassi com rodas

- 2 Chassis de acrílico;

- 2 Motores DC (3 6v) com caixa de redução (1:48);

- 2 Rodas de borracha;

- 1 Roda universal (giratória);

- 1 Suporte para pilhas/baterias;

- 1 Jogo de parafusos e porcas;

- 2 Discos de Encoder;

- 1 Chave de fenda.

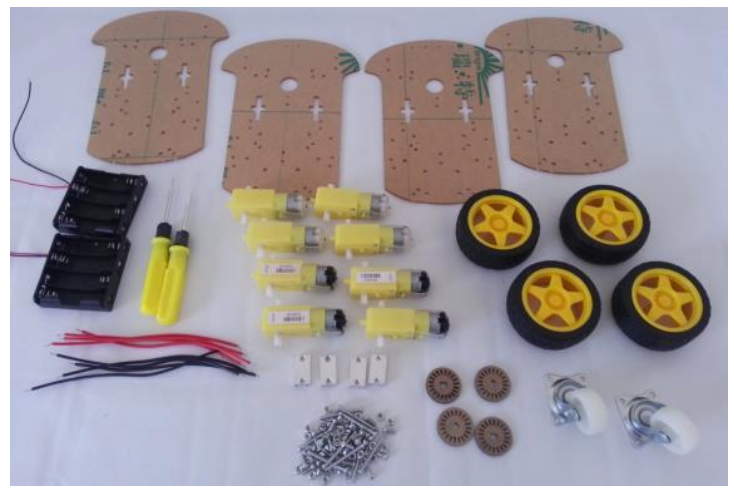

Fonte: A pesquisa

Adquirimos então mais 4 motores DC (3 6v) para o uso em atividades que poderiam necessitar de mais controles ou atividades integradas com o Lego. Não descartamos a ideia de serem montadas estruturas de um veículo com o próprio Lego.

A primeira atividade foi a elaboração do projeto de um protótipo de carro com as seguintes especificações: chassi, duas rodas, dois motores e uma roda auxiliar frontal. Cada dupla criou um documento compartilhado com as suas especificações. Assim desenvolvemos a atividade da seguinte forma: criação de um documento no Google Drive $^{2}$; definição das responsabilidades dos integrantes; preenchimento com os possíveis passos para a construção da estrutura; definição dos objetivos dos grupos.

Essa atividade serviu como base para o desenvolvimento do projeto dos alunos, estabelecendo uma noção das etapas que eles poderiam seguir, como também quais seriam os reais objetivos de cada grupo e da turma como um todo. Os próprios alunos decidiram que trabalhariam em grupos para que dois projetos fossem feitos, promovendo trocas de informações e definindo os que membros de um grupo poderiam auxiliar os de outro grupo.

\footnotetext{
${ }^{2}$ Google Drive é uma ferramenta web para o armazenamento e compartilhamento de documentos eletrônicos. Fonte: https://www.google.com/drive/
} 
Após essa articulação, disponibilizamos aos alunos os dois kits com a estrutura completa do chassi para que eles procurassem como montar a estrutura sem o passo-apasso da execução, apenas com uma foto da estrutura final.

Após a montagem da estrutura do carro, foram adicionados os componentes do Arduino para que ele apenas se movimentasse em linha reta. Os alunos logo chegaram à conclusão de que, para andar em linha reta, bastaria ligar os dois motores nas entradas de 5v da placa do Arduino. A estrutura montada está demonstrada na Figura 4.

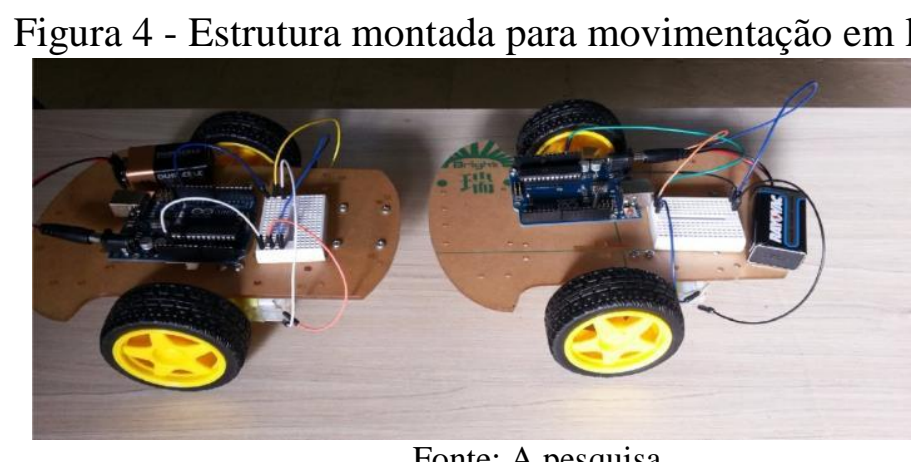

Fonte: A pesquisa

A segunda aula foi destinada ao conceito de controlar os motores pelo Arduino, pois, após as atividades realizadas no primeiro encontro, os alunos desejavam movimentar os carrinhos construídos com o controle de direcionamento. Concluídas essas atividades, os alunos demonstravam compreender o conceito de controle de um motor usando o Arduino, com a programação de uma sequência de passos, ele permanecer ligado por 1 segundo, desligado por 1 segundo, ligado por 2 segundos e desligado por 2 segundos.

A terceira aula foi destinada à construção de um protótipo que contivesse um motor no centro e fizesse o carro se locomover em linha reta. Os alunos selecionaram as estruturas das aulas anteriores, desenvolvidas por eles, que melhor se adaptariam ao seguimento do projeto. Assim, o grupo desenvolveu um protótipo de carro com quatro rodas, um motor, uma placa de Arduino para controle e uma bateria. O protótipo ainda continha um sistema de polia para fazer a ligação entre o motor do Arduino e as engrenagens utilizadas pelo Lego.

Dando prosseguimento as atividades, foi definido um controle de direção no protótipo, pois para se atingir os objetivos determinados, o invento deveria ser programado para traçar uma rota não linear, para poder desviar de objetos ao longo do caminho.

$\mathrm{O}$ aluno $\mathrm{G}$ propôs para a turma fazer a estrutura igual a de um trator, assim os alunos optaram por manter uma estrutura com quatro rodas e adicionaram uma articulação no protótipo com dois motores. As premissas definidas seriam, se quisessem locomover o protótipo em linha reta, acionariam os dois motores, se quisessem virar à direita acionariam o motor da esquerda e se quisessem dobrar à esquerda acionariam o motor da direita. Na sequência da proposta, ocorreu a construção do protótipo, indicado na Figura 5 . 
Figura 5 - Carro com articulação

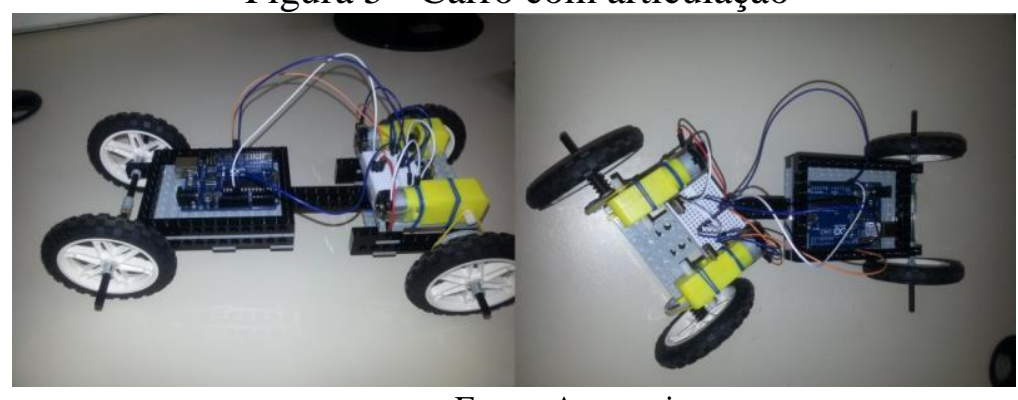

Fonte: A pesquisa

Para testar a estrutura do carrinho, propusemos uma atividade em que os alunos teriam que programar o protótipo para desviar de um objeto à frente. Para realizar a tarefa, os alunos programaram uma sequência de instruções para o carro e transformaram essa sequência em uma sequência de instruções para o Arduino, colocando dois motores ligados às entradas 8 e 10 da placa.

Na quinta aula, os alunos exploraram o conceito do transistor Tip 120, que estava sendo usado no projeto como base para controlar os atuadores do Arduino, como os motores. O modelo tinha o propósito de fazer o motor ligar por um segundo e desligar por um segundo, por isso, inicialmente foi montada a estrutura física e para que o motor funcionasse, os alunos desenvolveram um código simples para testar as ligações feitas.

Por mais que essas atividades já tivessem sido trabalhadas em outras aulas, a revisão de alguns conceitos como função de setup, de loop e de comandos como digitalWrite e delay foi importante para sua melhor compreensão.

A sexta e a sétima aulas foram destinadas as atividades nas quais os alunos foram desafiados a elaborarem novas estruturas robóticas que pudessem ajudar as pessoas no dia a dia. Surgiram diversas ideias como uma máquina para tapar buracos na rua, uma garra mecânica motorizada, um carro para carga, um robô que recolhe moedas, um gato para crianças que têm alergia a pelos, um robô para limpar o chão da casa e um robô para fazer os trabalhos domésticos.

A partir dessas ideias, os alunos foram questionados sobre quais componentes necessitariam para a montagem das soluções imaginadas. Então começaram a realizar um protótipo das ideias cujas construções julgavam viáveis. Organizando-se em duplas ou em trios, optando, cada grupo, por uma ideia, entre as escolhidas individualmente. Os quatro protótipos criados estão representados na Figura 6.

\section{Figura 6 - Protótipos de criação livre}

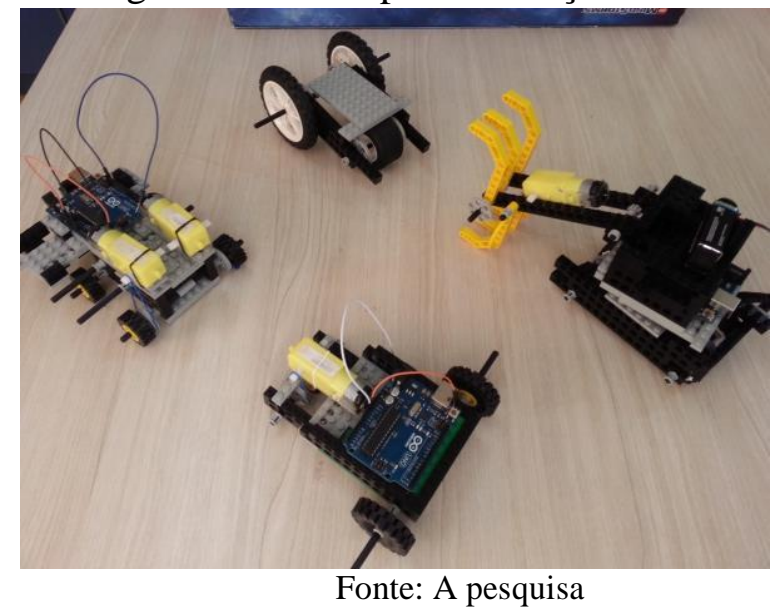


Após a criação dos inventos, os alunos apresentaram suas ideias ao grande grupo e defenderam suas soluções, ponderando sobre os benefícios que cada protótipo poderia trazer se fossem construídos. A partir dos protótipos construídos, os alunos escolheram um para dar seguimento em sua estrutura, enquanto os demais apenas fariam as estruturas se locomoverem. O protótipo escolhido para dar continuidade ao projeto foi o do Aluno $\mathrm{G}$, que era uma garra mecânica motorizada.

Ao término das estruturas, os alunos partiram para a última atividade do projeto: organizar um protótipo com a estrutura do Arduino que desviasse dos objetos automaticamente. Nesta etapa eles precisaram de auxílio para o uso do sensor ultrassônico de distância. $\mathrm{O}$ aparelho foi acoplado a parte frontal da estrutura, como demonstra a Figura 7.

Figura 7 - Protótipo com sensor ultrassônico

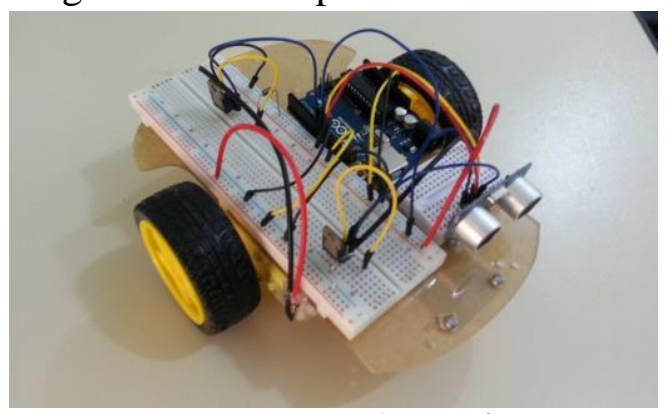

Fonte: A pesquisa

Os alunos construíram, em conjunto com o pesquisador, o algoritmo que fez o carro se locomover em uma direção até encontrar um obstáculo. Quando o sensor acusava uma distância menor do que $50 \mathrm{~cm}$ (distância decidida pelos alunos), o carro virava 300 milésimos de segundo e voltava a andar linearmente.

Por diversas vezes, ocorreram testes para a validação do algoritmo, assim o Arduino era programado e, em seguida, era testado em um ambiente fora do laboratório para verificar se funcionaria como o esperado. Ao final, uma sequência foi validada após discussão e testes feitos pela turma. Cabe salientar que o código foi programado com o auxílio do pesquisador devido à complexidade do uso do sensor ultrassônico.

$\mathrm{O}$ último encontro foi reservado para troca de ideias sobre o projeto. Assim, os alunos prepararam os protótipos para as apresentações no intervalo do horário de aula em diferentes ambientes da escola, onde eles esclareceram algumas dúvidas sobre robótica para as crianças da escola.

Dentre os relatos dos alunos ao longo do projeto destacamos, no sentido da participação e do trabalho em equipe, aproximando-se as ideias de Hernández e Ventura (1998) sobre a colaboração e a disposição dos alunos em trabalhar em equipe e expressar suas ideias de maneira concreta no grupo:

Eu gostei muito do projeto, pois nós aprendemos a trabalhar em equipe, ajudar-nos uns aos outros a programar um Arduino, a usar os fios e a protoboard, a expressar nossas ideias e colocá-las em prática, a usar o lego para construir robôs. Gostei bastante de montar nossos robôs, montar robôs em equipes, fazer códigos para fazer um relógio, fazer nossos robôs funcionarem, acender e apagar um LED ou mais ao mesmo tempo.

E esse foi o projeto para mim, um projeto muito legal que com certeza vou levar seu conhecimento para o futuro e espero que esse projeto tenha continuação (Aluno $\mathrm{G}$ )

Eu achei que foi ótimo, pois esse foi um projeto que mexeu com minha cabeça (ou seja, foi de raciocínio, atividades). Não acho que exista um jeito melhor de passar meu tempo. Eu aprendi jeitos diferentes de conectar em lugar a outro (usando chips, cabos 
e protoboard). Os trabalhos em grupo ajudaram a aumentar meu convívio e jeito com os outros ao meu redor. Eu gostei de poder aprender coisas que antes eram mais difíceis. Aprendi a construir uma base para lixo com o lego e Arduino (Aluno L).

\section{CONSIDERAÇÕES FINAIS}

Ao implementar um projeto de robótica embasado em conceitos, que foram emergindo da curiosidade do grupo de alunos e por tecnologias como Arduino, foi possível observar que a organização de um projeto envolve diversos fatores, desde a seleção da escola, preparação do ambiente, seleção de alunos, elaboração das primeiras atividades e preparação do material, que são ações prévias ao próprio início do projeto.

A aplicação das atividades, em vários momentos, concebidas pelo grupo de alunos participantes da pesquisa e a análise de cada uma delas e, ao final de cada etapa do projeto, são fatores que favoreceram o andamento do trabalho, uma vez que, ao analisá-las, encontramos subsídios que auxiliaram na elaboração das ações subsequentes, permitindo a adequação e o repensar, possibilitando a continuidade do trabalho.

A elaboração do projeto por meio da concepção dos projetos de trabalho, também traz indícios de pontos positivos, como a integração entre alunos de turmas e anos diferentes da escola, proporcionando a troca de experiência entre eles, e também a possibilidade de abordar os conteúdos curriculares de maneira não linear, ou seja, trabalhando conceitos de diversas disciplinas e de diferentes anos de ensino, sempre que se fizeram necessários ao desenvolvimento das atividades. Constatamos que os alunos conseguiram articular conceitos teóricos colocando-os em prática e construindo algo significativo para o próprio grupo.

\section{REFERÊNCIAS BIBLIOGRÁFICAS}

MAGNUS, Vinícius Silveira. A implementação de um projeto de robótica com o apoio dos conceitos de Ciências e de Matemática. 2015. 121f. Dissertação (Mestrado em Ensino de Ciências e Matemática). Programa de Pós-Graduação em Ensino de Ciências e Matemática Universidade Luterana do Brasil, Canoas, 2015.

BAUER, M. W.; GASKELL, G. Pesquisa qualitativa com texto, imagem e som: um manual prático. Petrópolis, RJ: Vozes, 2010.

CÉSAR, D. R. Robótica Livre: soluções tecnológicas livres em ambientes informatizados de aprendizagem na área da robótica pedagógica. Anais do III Workshop de Educação em Informática e Computação de Minas Gerais - Ferramentas de Apoio ao Ensino, Belo Horizonte - MG, 2004.

CRAIG, J. J. Robótica. São Paulo: Pearson Education do Brasil, 2012.

FERNANDES, C. C.; SÁ, S. T.; GONÇALVES, L. M. G. Uma nova abordagem em robótica educacional utilizando simuladores e kits de robótica livre. III Workshop de Robótica Educacional (WRE), Fortaleza/CE, 2012.

HERNÁNDEZ, F.; VENTURA, M. A organização do currículo por projetos de trabalho: o conhecimento é um caleidoscópio. Porto Alegre: ArtMed, 1998.

MORA, D. Aprendizaje y enseñanza: proyectos y estrategias para uma educación matemática del futuro. LaPaz, Bolivia: Campo Iris, 2004.

NUNES, D. J. Ciência da computação na educação básica. Jornal da Ciência, setembro 2011.

PAPERT, S. A Máquina das crianças: repensando a escola na era da informática. Porto Alegre: Artmed, 1994.

WING, J. M. Computational thinking. Communications of the ACM, v. 49, n. 3, p. 33-35, 2006. ZABALA, A. Enfoque globalizador e pensamento complexo: uma proposta para o currículo escolar. Porto Alegre: Artmed, 2008. 